\title{
In Vivo Evidence that Local Cortisol Production Increases in the Preovulatory Follicle of the Cow
}

\author{
Tomas J. ACOSTA ${ }^{1)}$, Masa TETSUKA ${ }^{2)}$, Motozumi MATSUI ${ }^{1 \# \#,}$ \\ Takashi SHIMIZU ${ }^{1)}$, Bajram BERISHA ${ }^{3)}$, Dieter SCHAMS ${ }^{3)}$ and \\ Akio MIYAMOTO ${ }^{1)}$
}

${ }^{1)}$ Graduate School of Animal and Food Hygiene, Obihiro University of Agriculture and Veterinary Medicine, Obihiro 080-8555, 2)Department of Agriculture and Life Science, Obihiro University of Agriculture and Veterinary Medicine, Obihiro 080-8555, Japan

${ }^{3)}$ Institute of Physiology, Technical University of Munich, 80350 Freising-Weihenstephan, Germany

\#Present: Laboratory of Reproductive Endocrinology, Graduate School of Natural Science and Technology, Okayama University, Tsushima-Naka, Okayama 700-8530,

\#\#Present: Department of Clinical Veterinary Science, Obihiro University of Agriculture and Veterinary Medicine, Obihiro 080-8555, Japan

\begin{abstract}
The aim of the present in vivo study was to monitor real-time fluctuations of cortisol (Cr) in the wall of preovulatory follicles using a microdialysis system (MDS) implanted in the theca layer as well as changes in ovarian venous plasma (OVP) and jugular venous plasma (JVP). Seven cows were superovulated using FSH and prostaglandin F2 $\alpha$ injections. Dialysis capillary membranes were surgically implanted into the theca layer of mature follicles and connected to a microdialysis system. Fractions of the perfusates were collected from Day -1 (Day $0=\mathrm{LH}$ surge) to Day 3 . No difference in the concentrations of $\mathrm{Cr}$ between JVP and OVP was detected throughout the experiment. Circulating concentrations of $\mathrm{Cr}$ ranged from 20 to $35 \mathrm{ng} / \mathrm{ml} 8 \mathrm{~h}$ after surgery in ovulatory and anovulatory cows. In five ovulatory cows, the $\mathrm{Cr}$ concentration decreased to basal levels $(<10 \mathrm{ng} / \mathrm{ml})$ between 12 and 24 $\mathrm{h}$ after surgery, however, two anovulatory cows retained high $\mathrm{Cr}$ levels $(>10 \mathrm{ng} / \mathrm{ml})$ up to $42 \mathrm{~h}$ after surgery. There was a clear increase in the local concentration of $\mathrm{Cr}$ from $13.3 \pm 2.1 \mathrm{pg} / \mathrm{ml}$ at $-24 \mathrm{~h}$ to $27.5 \pm 1.7 \mathrm{pg} / \mathrm{ml}$ at $0 \mathrm{~h}$ (peak of the LH surge) within the wall of ovulatory follicles. This increase was not detected in anovulatory follicles. This transient increase in $\mathrm{Cr}$ occurred only in the follicle wall, but not in the OVP or JVP, indicating that the presence of a local regulatory mechanism for $\mathrm{Cr}$ production/conversion in ovulatory follicles, and this mechanism may modulate the inflammatorylike reaction induced by LH surge in the follicle wall. The present results demonstrate that the glucocorticoid environment in the follicular wall adjusts at the local level in bovine ovulatory follicles. This mechanism may protect follicles from the adverse effects of glucocorticoid, and it may prevent excess inflammatory reactions associated with ovulation by temporarily increasing local concentrations of glucocorticoid, thus forming an integral part of the regulatory mechanism in ovarian physiology.

Key words: Bovine, Cortisol, Follicle, Ovary, Ovulation
\end{abstract}

(J. Reprod. Dev. 51: 483-489, 2005)

Accepted for publication: April 19, 2005

Published online: June 10, 2005

Correspondence: A. Miyamoto (e-mail: akiomiya@obihiro.ac.jp) 
G lucocorticoid, a C21 steroid that is produced exclusively in the adrenal cortex, acts as a modulator of physiological functions in several organs, including the ovary. The action of glucocorticoid on ovarian function is thought to be primarily antagonistic. While high levels of glucocorticoid suppress ovarian function through the suppression of gonadotropin secretion [1], that also act directly on granulosa cells to downregulate production of steroids and prostaglandins, and expression of granulosa cell LH-receptor [2-4].

A new role for glucocorticoid in ovarian physiology has been proposed since the finding that the concentrations of active glucocorticoid, cortisol (Cr), in the follicular fluid increase after the preovulatory LH-surge in human ovulatory follicles $[5,6]$. As ovulation is an inflammatory event characterized by increased synthesis of cytokines and prostaglandins [7, 8], the increase in anti-inflammatory glucocorticoid around the ovulatory period may represent a physiological mechanism to limit the damage caused by ovulation [6]. This transient increase in active glucocorticoid appears to be mediated by relative expressions of two $11 \beta$ HSDs, namely reductive $11 \beta$ HSD type 1 (11HSD1) and oxidative $11 \beta$ HSD type2 (11HSD2) [9]. A similar enzymatic switch comprised of these two $11 \beta$ HSDs has been shown to exist in the rat ovary, and this switch is regulated by $\mathrm{LH} / \mathrm{hCG}$ and interleukin- $1 \beta$, a proinflammatory cytokine involved in the ovulatory process $[10,11]$. These results imply that alteration of glucocorticoid metabolism is an integral part of the ovulatory process in a wide range of species.

Recently, both 11HSD1 and 11HSD2 were identified in the bovine ovary, indicating the presence of a similar glucocorticoid metabolic system in this species [12]. Thus, the objective of the present study was to elucidate whether a similar change in glucocorticoid concentrations occurs in bovine ovulatory follicles around the time of LH-surge. To monitor real-time fluctuations of $\mathrm{Cr}$ in the follicle wall, the capillary membranes of a microdialysis system (MDS) were implanted in the theca layer. Changes in the levels of $\mathrm{Cr}$ in the MDS perfusates along with those in ovarian venous plasma (OVP) and jugular venous plasma (JVP) were determined.

\section{Materials and Methods}

\section{Animals}

The animal experiment was carried out at the Institute of Physiology, Technical University of Munich-Weihenstephan, Germany. Experimental procedures complied with the Technical University of Munich Guide for Care and Use of Agriculutural Animals. Seven multiparous, nonlactating Simental cows were used for this study. The cows were induced into having multiple ovulations using a half-dose (9 mg) of FSH (Ovagen; ImmunoChemical Products LTD, Auckland, New Zealand). A schematic time schedule of the superovulatory treatment and the MDS is shown in Fig. 1. Two intramuscular injections were given daily at $0700 \mathrm{~h}$ and $1800 \mathrm{~h}$ for 4 days, starting between day 8 and 11 of the estrous cycle (the day of estrus was designated as Day 0). On the 3rd day of the FSH treatment, at $1400 \mathrm{~h}$, a luteolytic dose of $500 \mu \mathrm{g}$ of cloprostenol (estrumate; Mallinckrodt $\mathrm{GmbH}$, Burgwedel, Germany), a PGF2 $\alpha$ analogue, was intramuscularly injected. At between 18-22 h after cloprostenol injection, a laparotomy was performed, as described previously [13], to surgically implant the MDS capillary membranes into the follicular wall of mature follicles and to canulate the ovarian vein ipsilateral to the implanted MDS. A jugular venous catheter was also implanted. Before surgery, the ovaries were monitored by transrectal ultrasonography to determine the size and number of the developing follicles and the side of the regressing CL. After surgery, the cows were moved to individual stanchions where they were fed daily with corn silage and hay with constant free access to water. At the end of the experiment (Day 3 after the LH surge), the cows were ovariectomized, and the ovaries were visually inspected for the presence of CL and the location of the MDS within the CL; most of the tubes were surrounded by luteal tissue.

\section{Implantation of the MDS capillaries into the follicular wall}

The MDS for bovine mature follicles was based on the method developed for porcine follicles in vivo [14], and the same system was applied to bovine preovulatory follicles in vivo as previously described [15]. The MDS capillary membranes were implanted in the theca layer of follicles in the ovary contralateral to the regressing CL. Only 


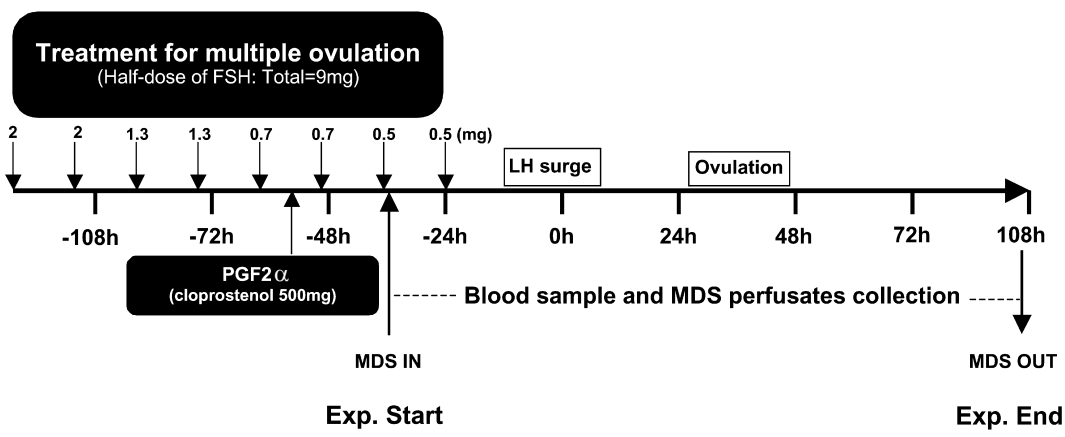

Fig. 1. Time schedule of treatment for multiple ovulation and the MDS of bovine preovulatory follicles in vivo.

follicles that were at least $13 \mathrm{~mm}$ in diameter were selected for implantation. Implantation was done via a lateral laparotomy under epidural anesthesia as described previously [13, 15]. Basically, two dialysis capillary membranes (Fresenius SPS 900 Hollow Fibers, cutoff $\mathrm{MW}=1000 \mathrm{kDa}, 0.2 \mathrm{~mm}$ diameter, $5 \mathrm{~mm}$ long; Fresenius AG, St. Wendel, Germany) were implanted into the lateral side of the follicular wall using a 25-gauge hypodermic needle. Both ends of the capillary were glued to a $25-\mathrm{cm}$-long piece of silicone elastomer tubing (i.d. $0.3 \mathrm{~mm}$ ) and connected to the MDS. The tubing was fixed on the surface of the follicular wall by Histoacryl blau (B. Braun-Dexon GmbH, Spangenberg, Germany), and the dialysis pieces with silicone tubing were connected to Teflon tubing that led to the outside of the abdomen. The exteriorized bundle of afferent and efferent Teflon tubing was fixed on the back of the cow. One end of the MDS was connected to a multiple-line peristaltic pump, and the other was connected to a multiple-line fraction collector. The MDS was continuously perfused with Ringer's solution at a flow rate of $2.5 \mathrm{ml} / \mathrm{h}$ throughout the experiments, and the fractions of the perfusates were collected at intervals of $4 \mathrm{~h}$, starting on Day -1 and continuing for the next 5 Days. During this period, most of the implanted follicles ovulated and developed to functional CL, thus allowing the determination of local secretory changes during the process of ovulation and new CL formation.

During surgery, an 18-gauge catheter (Medicut Catheter Kit; Argyle Co., Japan Sherwood, Tokyo, Japan) was inserted and sutured into the ovarian vein ipsilateral to the implanted MDS. JVP and OVP for determination of $\mathrm{LH}$ and cortisol were collected into sterile $10 \mathrm{ml}$ tubes containing $200 \mu \mathrm{l}$ of a stabilizer solution (0.3 M EDTA, 1\% acetylsalicylic acid, $\mathrm{pH}$ 7.4) from the start of the experiment at $4 \mathrm{~h}$ intervals. All tubes were immediately chilled in ice water for $10 \mathrm{~min}$, centrifuged at $2000 \mathrm{~g}$ for $10 \mathrm{~min}$ at $4 \mathrm{C}$, and the obtained plasma was frozen at $-30 \mathrm{C}$ and stored until hormonal measurements.

\section{Cortisol extraction}

The OVP and JVP samples for Cr $(200 \mu \mathrm{l})$ were extracted using diethyl ether. The plasma samples $(200 \mu \mathrm{l})$ and the MDS perfusates $(8 \mathrm{ml})$ were adjusted to $\mathrm{pH} 3.5$ using $1 \mathrm{~N}$ and $5 \mathrm{~N} \mathrm{HCl}$, respectively. The samples were extracted using diethyl ether as described previously [15]. The residue was dissolved in $200 \mu$ l assay buffer (40 $\mathrm{mM}$ PBS, $0.1 \%$ BSA, $\mathrm{pH}$ 7.2) for plasma samples and in $300 \mu$ for MDS perfusates. Thus, the MDS samples were concentrated 26.7 fold. To estimate the recovery rate of $\mathrm{Cr}, 10 \mathrm{ng}$ and $100 \mathrm{pg}$ of $\mathrm{Cr}$ were added to $1 \mathrm{ml}$ of plasma samples and Ringer's Solution, respectively. The recovery rate of $\mathrm{Cr}$ was $94 \%$ for plasma and $90 \%$ for MDS perfusate $(n=10)$.

\section{Hormone determinations}

The concentrations of $\mathrm{Cr}$ in the plasma and perfusate fractions of the MDS were determined in duplicate by second antibody EIA after extraction using 96-well ELISA plates (Corning Glass Works, Corning, NY) as described earlier [15-17].

The Cr EIA was identical to the progesterone EIA described earlier [17]. Basically, $20 \mu$ l of standards or samples were incubated with $100 \mu$ l solution of polyclonal antibody (raised in rabbit against cortisol-21-hemisuccinate; 1:50,000) donated by Dr. 
H.H.D. Meyer (Institut fur Physiologie FreisingWeihenstephan, Germany), and $100 \mu \mathrm{l}$ A-3-CMOhorseradish peroxidase (1:4,000; cortisol-HRP; 4pregnen-11 $\beta, 17,21$-triol-3,20-dione 21glucosiduronate; Steraloids, Inc. Newport, Rhode Island, USA) for $16 \mathrm{~h}$ at $4 \mathrm{C}$. The standard curve ranged from 10 to $10,000 \mathrm{pg} / \mathrm{ml}$, and the ED50 of the assay was $230 \mathrm{pg} / \mathrm{ml}$. The intra- and interassay CVs were $6.8 \%$ and $8.1 \%$, respectively. The crossreactivities of the antibody were $100 \%$ for cortisol, $6.9 \%$ for corticosterone, $7.5 \%$ for $17 \alpha-$ dihydroxyprogesterone, $6.7 \%$ for 20 adihydroxyprogesterone, $4.7 \%$ for cortisone, $2.6 \%$ for deoxycorticosterone, $0.03 \%$ for $5 \mathrm{a}$ pregnanedione, $0.41 \%$ for androstenetrione, $1.51 \%$ for progesterone, $0.01 \%$ for pregnenolone, and $0.0007 \%$ for estradiol. The plasma LH concentration was determined directly in duplicate $20 \mu$ JVP samples using a sensitive EIA for LH determination in bovine plasma based on the streptavidin-biotin technique as previously described [16]. The standard curve for LH ranged from 0.2 to $200 \mathrm{ng} / \mathrm{ml}$, and the ED50 of the assay was $10.5 \mathrm{ng} / \mathrm{ml}$. The intra- and interassay CVs were 8.5 and $13.5 \%$, respectively.

\section{Statistical analysis}

Due to the individual variation in the interval from the cloprostenol injection to the endogenous LH surge among animals, the peak of the LH surge in the JVP was considered to be $0 \mathrm{~h}$ for the analysis of changes in the concentrations of $\mathrm{Cr}$ during the experimental period. The mean absolute concentrations of $\mathrm{Cr}$ in the MDS fractions, OVP and JVP samples collected at different time periods related to the peak of the LH surge were analyzed by ANOVA followed by Fisher's Protected Least Significant Difference (PLSD) test. Differences were considered significant at a probability less than $5 \%(P<0.05)$.

\section{Results}

\section{Ovarian response to superovulation}

The number of follicles with diameters $>11 \mathrm{~mm}$ per ovary at the time of surgery was $8 \pm 1.5$ (mean \pm SEM). Of the seven cows used in the present study, five cows showed an endogenous LH surge between 36 and $64 \mathrm{~h}(54.7 \pm 5.0 \mathrm{~h})$ after a luteolytic injection of cloprostenol. The basal concentration of LH in JVP was $2 \pm 1.3 \mathrm{ng} / \mathrm{ml}$, and the peak value of the LH surge was $26.4 \pm 6.6 \mathrm{ng} / \mathrm{ml}$ (Fig. 2a). In the remaining two cows, the JVP concentrations of LH remained low throughout the experimental period and ovulation did not occur, which was confirmed by visual inspection of the ovaries at the end of the experiment after ovariectomy.

\section{Plasma concentrations of cortisol}

Pulsatile changes in the circulating levels of $\mathrm{Cr}$ in JVP and OVP occur synchronously. No difference in the concentrations of $\mathrm{Cr}$ between JVP and OVP was detected throughout the experiment.

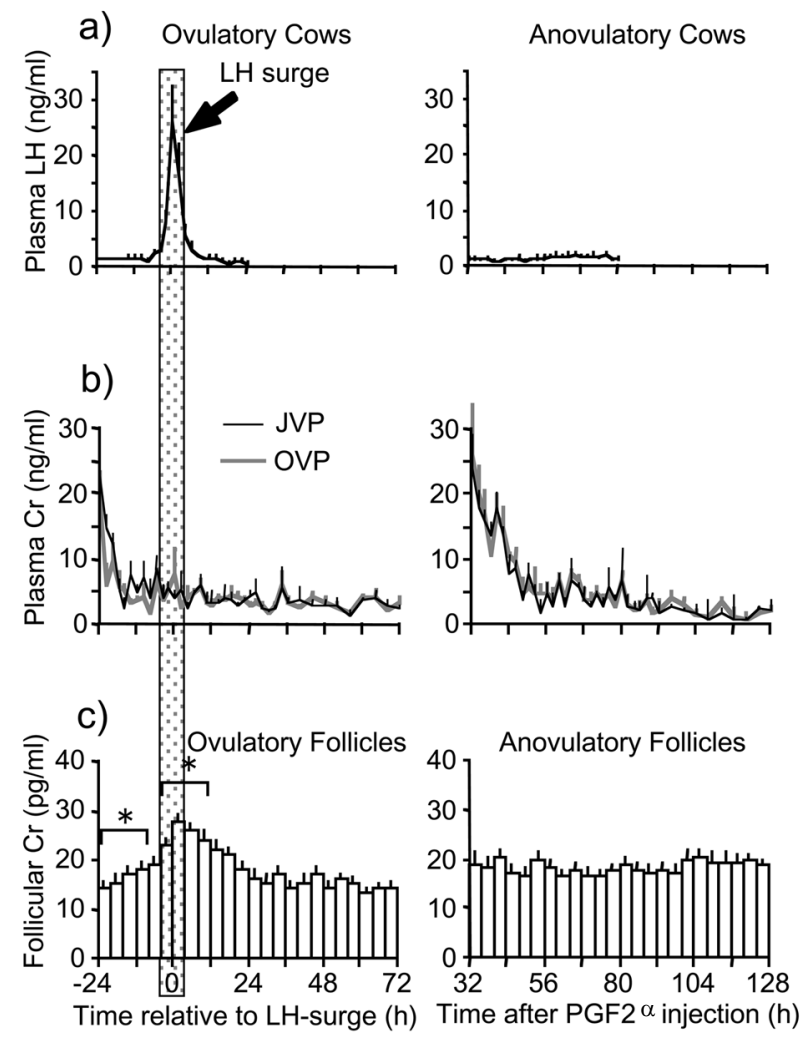

Fig. 2. Plasma profiles of $\mathrm{LH}$ and the cortisol (Cr) concentrations in ovulatory cows ( $n=5$; left panels) and anovulatory cows $(n=2$; right panels) treated with a half-dose of FSH and PGF $2 \alpha$. For the ovulatory cows, the data were normalized to the peak of the LH surge $(0 \mathrm{~h})$. Data from anovulatory cows were normalized to the time of PGF2 $\alpha$ injection. a) LH concentrations in jugular venous plasma (JVP); b) $\mathrm{Cr}$ concentrations in JVP and ovarian venous plasma (OVP); and c) Changes in the local release of $\mathrm{Cr}$ in the follicular wall of 12 ovulatory and 10 anovulatory follicles by a microdialysis system implanted in the cows. Data are means \pm SEM. ${ }^{*} \mathrm{P}<0.05 ;-24$ to $-8 \mathrm{~h}$ vs. -4 to $12 \mathrm{~h}$ 
Circulating concentrations of $\mathrm{Cr}$ ranged from 20 to $35 \mathrm{pg} / \mathrm{ml} 8 \mathrm{~h}$ after surgery. In ovulatory cows, $\mathrm{Cr}$ concentrations decreased to basal levels $(<10 \mathrm{ng} /$ $\mathrm{ml}$ ) between 12 and $24 \mathrm{~h}$ after surgery (between 24 and $12 \mathrm{~h}$ before LH surge), however, anovulatory cows retained high $\mathrm{Cr}$ levels $(>10 \mathrm{ng} / \mathrm{ml})$ up to $42 \mathrm{~h}$ after PGF2 $\alpha$ (Fig.2b). Plasma concentrations of $\mathrm{Cr}$ were higher $(\mathrm{P}<0.05)$ in anovulatory cows than in ovulatory cows.

Changes in the release of cortisol in the follicular wall

There was a clear increase in the local concentration of $\mathrm{Cr}$ during LH surge ( -4 to $12 \mathrm{~h}$ after LH surge) compared to the pre-LH surge period ( -24 to $8 \mathrm{~h}$ before LH-surge) in the wall of the ovulatory follicles $(\mathrm{P}<0.05$, Fig. $2 \mathrm{c})$. This increase was not detected in anovulatory cows.

\section{Discussion}

In the present study, a two fold increase in the concentration of $\mathrm{Cr}$ in response to the preovulatory LH-surge was observed in the follicular wall (MDS perfusate), but not in the OVP or JVP. To our knowledge this is the first report to monitor $\mathrm{Cr}$ concentrations in the follicular wall, OVP, and JVP simultaneously throughout the ovulatory period in any species. The present results clearly demonstrate that the level of glucocorticoid in the ovulatory follicles is independent of that in systemic circulation in cattle.

Unlike estrogen, glucocorticoids are synthesized exclusively in the adrenal cortex and metabolized either to active forms (e.g. cortisol) or inactive forms (e.g. cortisone) by the $11 \beta \mathrm{HSD}$ in individual organs. To date, two $11 \beta$ HSD isoforms have been identified; 11HSD1 is predominantly a reductase with a dehydrogenase activity that activates cortisone to cortisol, while 11 HSD2 is a dehydrogenase that catalyzes cortisol to cortisone [18]. Thus local levels of the active glucocorticoid in an organ are determined by the relative expression of these two enzymes. For example, glucocorticoid target organs, such as the liver, predominantly express 11HSD1 to increase local levels of cortisol while the mineralocorticoid target organs, such as the kidney, only express 11HSD2 and protect the non-selective mineralocorticoid receptor from false-activation by cortisol.

The ovaries of humans and rats express both
11HSD1 and 11HSD2, and the expression of these enzymes are shown to be dramatically altered by LH/hCG in ovulatory follicles; the follicles mainly express 11HSD2 before the LH-surge while they predominantly expresses 11HSD1 after the surge [9]. This enzymatic switchover results in a transient increase in the concentration of active glucocorticoid (i.e. Cr) in the follicular fluid [19]. Increases in the activity of proteolytic enzymes in the ovulatory follicle also increase the concentrations of active $\mathrm{Cr}$ by freeing it from binding proteins $[20,21]$. The physiological significance of this phenomenon is not fully understood, but it may be related to the antiinflammatory nature of glucocorticoid. The ovulatory process is likened to an inflammatory reaction induced by the $\mathrm{LH}$-surge and comprises a sequential activation of cytokines, PGs, and proteolytic enzymes [7]. Glucocorticoid is shown to down-regulate expression of these factors in cultured follicular cells [4]. Thus, an increase in the local concentration of $\mathrm{Cr}$ may limit the damage associated with ovulation and promote rapid healing and a rise of newly formed CL by preventing excess inflammatory reaction [6].

In the present study, a transient increase in $\mathrm{Cr}$ coinciding with the LH-surge was also observed. This implies a reductive activity for 11HSD1, indicating the presence of a similar mechanism in the bovine ovary as in humans and rats. The bovine ovary was shown to express 11HSD1, although its enzymatic nature around the LH-surge has not been elucidated [12].

In the present study, a prolonged increase in cortisol in JVP and OVP, presumably caused by the stress due to surgery, was observed in two anovular cows. Despite this increase in circulating $\mathrm{Cr}$, follicular levels of $\mathrm{Cr}$ were stable throughout the experimental period, indicating the presence of a local inactivation mechanism. As postulated in human and rat preovulatory follicles $[9,10]$, predominant expression of 11HSD2 before the LHsurge also appears to be a local inactivation mechanism. This local inactivation may protect preovulatory follicles from possible adverse effects of glucocorticoid inhibiting aromatase activity and LH-receptor expression in granulosa cells [2-4]. Interestingly, bovine preovulatory follicles only express 11HSD1, although both 11HSD1 and 11HSD2 are expressed in CL [12]. Since there was a significant negative correlation between levels of 
follicular fluid $\mathrm{Cr}$ and 11HSD1 mRNA, the authors suggest that bovine 11HSD1 acts as a dehydrogenase [12], as implied for ovine placental 11HSD1 [22]. The amino acid sequence of bovine 11HSD1, which showed 95\% similarity with that of sheep, compared to $78 \%$ for human and $76 \%$ for mouse, may support this hypothesis (Hata \& Tetsuka, unpublished data based on GenBank sequence AF548027). Nevertheless, it is necessary to conduct a functional study to elucidate the nature of bovine $11 \beta$ HSDs.

The levels of Cr in JVP and OVP were almost identical, indicating that the ovary, as a whole, is exposed to fluctuations of $\mathrm{Cr}$ caused by various bodily reactions. Despite this, the levels of $\mathrm{Cr}$ in the follicular wall were not affected. In turn, the transient increase of $\mathrm{Cr}$ in the follicular wall did not affect circulating $\mathrm{Cr}$ levels in OVP either. These results suggest that the local glcocorticoid environment is finely tuned at the individual follicular level, and that it may locally modulate the inflammatory-like reaction induced by LH surge.

In conclusion, the results of the present study clearly demonstrate that the glucocorticoid environment in the follicular wall adjusts at the local level in bovine ovulatory follicles. This mechanism may protect follicles from the adverse effects of glucocorticoid, and it may prevent excess inflammatory reactions associated with ovulation by temporarily increasing local concentrations of glucocorticoid, thus forming an integral part of the regulatory mechanism in ovarian physiology.

\section{Acknowledgments}

The authors thank Dr. H.H.D. Meyer (Institute of Physiology, Technical University of Munich, Germany) for the $\mathrm{Cr}$ polyclonal antibody and Fresenius AG (St Wendel, Germany) for the microdialysis capillary membrane. This study was supported by Grant-in-Aids for Scientific Research and the Japan-Germany joint research project of the Japan Society for the Promotion of Science (JSPS), the German Research Foundation (Scha 254/14-1), and the 21st Century COE Program (A-1) of the Ministry of Education, Culture, Sports, Science and Technology, Japan. T.J.A. and M.M. were postdoctoral fellows supported by JSPS and the COE Program, respectively, and A.M. was supported by the Alexander von Humboldt Stiftung foundation.

\section{References}

1. Dobson H, Alam MG, Kanchev LN. Effect of betamethasone treatment on luteal lifespan and the LH response to GnRH in dairy cows. J Reprod Fertil 1987; 80: 25-30.

2. Schoonmaker JN, Erickson GF. Glucocorticoid modulation of follicle-stimulating hormonemediated granulosa cell differentiation. Endocrinology 1983; 113: 1356-1363.

3. Kawate N, Inaba T, Mori J. Effects of cortisol on the amounts of estradiol-17 $\beta$ and progesterone secreted and the number of luteinizing hormone receptors in cultured bovine granulosa cells. Anim Reprod Sci 1993; 32: 15-25.

4. Kol S, Ben-Shlomo I, Payne DW, Ando M, Rohan RM, Adashi EY. Glucocorticoids suppress basal (but not interleukin-1-supported) ovarian phospholipase A2 activity: evidence for glucocorticoid receptor-mediated regulation. Mol Cell Endocrinol 1998; 137: 117-125.

5. Harlow C, Jenkins J, Winston R. Increased follicular fluid total and free cortisol levels during the luteinizing hormone surge. Fertil Steril 1997; 68: 48-53.
6. Hillier SG, Tetsuka M. An anti-inflammatory role for glucocorticoids in the ovaries? J Reprod Immunol 1998; 39: 21-27.

7. Espey LL. Current status of the hypothesis that mammalian ovulation is comparable to an inflammatory reaction. Biol Reprod 1994; 50: 233-238.

8. Algire J, Srikandakumar A, Guilbault L, Downey B. Preovulatory changes in follicular prostaglandin and their role in ovulation in cattle. Can J Vet Res 1992; 56: 67-69.

9. Tetsuka M, Thomas FJ, Thomas MJ, Anderson RA, Mason JI, Hillier SG. Differential expression of messenger ribonucleic acids encoding $11 \beta$ hydroxysteroid dehydrogenase types 1 and 2 in human granulosa cells. J Clin Endocrinol Metab 1997; 82: 2006-2009.

10. Tetsuka M, Milne M, Simpson GE, Hillier SG. Expression of $11 \beta$-hydroxysteroid dehydrogenase, glucocorticoid receptor, and mineralocorticoid receptor genes in rat ovary. Biol Reprod 1999; 60: 330335.

11. Tetsuka M, Haines LC, Milne M, Simpson GE, Hillier SG. Regulation of $11 \beta$-hydroxysteroid 
dehydrogenase type 1 gene expression by $\mathrm{LH}$ and interleukin- $1 \beta$ in cultured rat granulosa cells. J Endocrinol 1999; 163: 417-423.

12. Tetsuka M, Yamamoto S, Hayashida N, Hayashi KG, Hayashi M, Acosta TJ, Miyamoto A. Expression of $11 \beta$-hydroxysteroid dehydrogenases in bovine follicle and corpus luteum. J Endocrinol 2003; 177: 445-452.

13. Ohtani M, Kobayashi S, Miyamoto A, Hayashi K, Fukui Y. Real-time relationships between intraluteal and plasma concentrations of endothelin, oxytocin, and progesterone during prostaglandin $F 2 \alpha-$ induced luteolysis in the cow. Biol Reprod 1998; 58: 103-108.

14. Einspanier A, Jarry H, Pitzel L, Holtz W, Wuttke W. Determination of secretion rates of oestradiol, progesterone, oxytocin, and angiotensin II from tertiary follicles and freshly formed corpora lutea in freely moving sows. Endocrinology 1991; 129: 34033409.

15. Acosta TJ, Ozawa T, Kobayashi S, Hayashi K, Ohtani M, Kraetzl WD, Sato K, Schams D, Miyamoto A. Periovulatory changes in the local release of vasoactive peptides, prostaglandin F2 $\alpha$, and steroid hormones from bovine mature follicles in vivo. Biol Reprod 2000; 63: 1253-1261.

16. Mutayoba B, Meyer H, Schams D, Schallenberger E. Development of a sensitive enzyme immunoassay for LH determination in bovine plasma using the streptavidin-biotin technique. Acta Endocrinol (Copenh) 1990; 122: 227-232.

17. Acosta TJ, Yoshizawa N, Ohtani M, Miyamoto A. Local changes in blood flow within the early and midcycle corpus luteum after prostaglandin F2 $\alpha$ injection in the cow. Biol Reprod 2002; 66: 651-658.

18. Krozowski Z, Li KX, Koyama K, Smith RE, Obeyesekere VR, Stein-Oakley A, Sasano H, Coulter C, Cole T, Sheppard KE. The type I and type II $11 \beta$-hydroxysteroid dehydrogenase enzymes. J Steroid Biochem Mol Biol 1999; 69: 391-401.

19. Yong PY, Thong KJ, Andrew R, Walker BR, Hillier SG. Development-related increase in cortisol biosynthesis by human granulosa cells. J Clin Endocrinol Metab 2000; 85: 4728-4733.

20. Andersen CY, Hornnes P. Intrafollicular concentrations of free cortisol close to follicular rupture. Hum Reprod 1994; 9: 1944-1949.

21. Andersen CY. Possible new mechanism of cortisol action in female reproductive organs: physiological implications of the free hormone hypothesis. J Endocrinol 2002; 173: 211-217.

22. Yang K, Langlois DA, Campbell LE, Challis JR, Krkosek M, Yu M. Cellular localization and developmental regulation of $11 \beta$-hydroxysteroid dehydrogenase type 1 (11 $\beta$-HSD1) gene expression in the ovine placenta. Placenta 1997; 18: 503-509. 